\title{
Are Experienced Analysts More Accurate?
}

\author{
Rich Fortin, New Mexico State University, USA \\ James H. Gilkeson, University of Central Florida, USA \\ Stuart E. Michelson, Stetson University, USA
}

\begin{abstract}
We examine the relationship between analyst experience and the accuracy of annual earnings forecasts using a 20-year sample (1983-2002) from the Thomson Financial First Call I/B/E/S database. We test for this relationship using three different measures of forecast accuracy employed by prior researchers, which are regressed against measures of general experience and specific experience, along with five other controls, for four independent 5-year subperiods, as well as for the full 20-year period. We find that general experience levels are positively associated with forecast accuracy (negatively associated with forecast error) in most subperiods for two of the three measures of forecast accuracy. We also find, in contrast with the extant literature, that for two of the three measures of forecast accuracy and for most subperiods, specific experience does not have an association with forecast accuracy beyond that provided by the general experience measure. Our results suggest that the relationship between forecast accuracy and analyst experience (as well as some other commonly examined analyst characteristics) is dependent on the measure of accuracy employed and the time period studied.
\end{abstract}

Keywords: investment decisions, analyst forecast accuracy, analyst general experience, analyst specific experience

\section{INTRODUCTION}

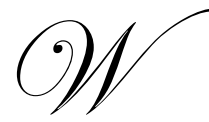

hen you're about to have open heart surgery, it's comforting to know that your surgeon has performed the operation a hundred times. The surgeon has "seen it all" and will know the procedure and what to do if something goes wrong. In the same vein, when you're selling a house, it seems natural to hire a realtor who has been selling houses in your neighborhood for years. Such a professional will know how to price and market your house and how to deal with difficult buyers and their realtors. Whether you call it experience, know-how, job tenure or specific human capital, the idea is the same: first, that practicing difficult tasks makes one better at performing them and, second, that market forces will, over time and on average, drive out incompetent performers.

Is the experienced surgeon, whose techniques were learned 20 or more years ago, really better than the younger one who is fresh out of a residency at one of the leading teaching hospitals in the country and knows the newest techniques? Will the more established realtor put as much time and effort into marketing your home as a less experienced one with fewer clients and a greater need and desire to sell your house. Upon deeper reflection, it's not so clear what impact job experience will have on job performance.

What about securities analysts? Is it reasonable to conclude that more experienced analysts are more reliable? Or are more experienced analysts using older techniques? Do they have closer relationships with the firms they analyze and does this closeness provide access to better or more timely information or does it create bias or conflict of interest? Do experienced analysts have less need to prove themselves?

It is important to examine the link between analyst experience and analyst performance. Investors and portfolio managers rely on the advice of analysts to make decisions about what securities to buy and sell or overweight and under-weight. There is limited empirical evidence that earnings forecasts are particularly accurate in a quantitative sense; indeed, when Harris (1999) examined analysts' estimates of long-term earnings growth rates, he concluded that, "on average... a superior forecast of long run earnings growth for individual companies can be 
obtained simply by assuming that average annual earnings growth will be zero." (page 737.) Despite this, the existence at any given time of thousands of well-paid analysts producing hundreds of thousands of earnings estimates each year, strongly suggests that many investors are paying attention. We believe that those investors are interested in ways of knowing which of these thousands of analysts are likely to be more reliable and which of the number of competing earnings estimates for a particular firm are likely to be more accurate.

Our research addresses the benefit of experience by examining the accuracy of analysts' forecasts of future earnings per share relative to both general experience, measured as the number of years the analyst has been forecasting earnings for any firm(s), and specific experience, measured as the number of years the analyst has been forecasting earnings for the particular firm. Our 20-year sample, from the Thomson First Call Institutional Brokers Estimates System database, covering almost 16 thousand analysts and 15 thousand firms, provides some evidence that an analyst's general experience matters - that analysts who have been in the business longer provide more reliable estimates. We find only very limited support, however, for the value of specific experience - the idea that analysts who have been covering a particular firm longer produce more accurate estimates of that firm's earnings. Further, in an expansion on prior research, we find that the relationship between analyst experience and forecast accuracy is not stable over time.

In addition, we examine whether more experienced analysts are more likely to produce conservative estimates; that is, estimates that are less than actual earnings. Using a logistic regression analysis, we examine the relationship between producing a conservative estimate and analyst experience, but find limited evidence of any stable relationship.

The remainder of this paper is structured in the usual way. In section 2, we provide a review of related literature and motivate our research. In section 3, we introduce and summarize our data set, followed by a discussion of the tests we conduct. Section 4 presents and discusses the results of those tests, while the final section provides concluding remarks and some ideas for future research.

\section{LITERATURE}

A complete review of the earnings forecast literature is well beyond the scope of any single paper. As noted earlier, thousands of analysts are paid handsomely each year to produce hundreds of thousands of earnings forecasts, in addition to other information and analysis. This suggests that market participants place value on these forecasts. Beyond this, there is empirical evidence that analysts' earnings estimates provide information beyond that provided by current earnings measures (e.g., Sougiannis and Yaekura, 2001.) Further, Chopra (1998) shows that analysts' forecasts have improved over time.

If there is valuable information in the average forecast, then it seems clear that there is greater value to be obtained by identifying those analysts who are (more likely to be) more accurate than others. Indeed a substantial literature of this sort exists. Cooper, Day, and Lewis (2001) show that useful analyst rankings can be obtained based on the timeliness of the analyst's forecasts. Sinha et al (1997), Brown (2001) and others show that an analyst's past accuracy is positively related to future accuracy. Stickel (1992) argues that frequency of forecast issuance is a useful predictor of forecast accuracy and also finds that forecasts of analysts ranked as Institutional Investor All-American are more accurate than those who are not ranked. Similarly, Fortin and Michelson (2006) show that analysts who hold the Chartered Financial Analyst (CFA) designation produce more accurate earnings forecasts than others. Clement (1999), in addition to examining the relationship between analyst experience and forecast accuracy, finds that forecast accuracy is positively associated with employer size and negatively associated with the number of firms and number of industries an analyst follows. Brown and Mohd (2003) show that forecast age (how close to the end of the period the forecast is issued) can explain forecast accuracy as well as a model that includes forecast age, analyst experience, number of industries followed by the analyst, number of firms followed by the analyst, brokerage (employer) size, and forecast frequency.

A rich and complex literature exists that examines the relationship between job tenure or experience and job performance. Christensen-Szalanski, et al (1983) provide a good review of the early literature, concluding that 
most studies show that experience with a task improves a person's performance, but that some show that "occasionally experience can bias an expert's judgment," (p. 278) "thus, experience with a task does not invariably improve a person's judgment." (p. 279.) Christensen-Szalanski et al add to this set of exceptions by finding, in a comparison of physician and college students' estimates of mortality rates from various diseases, that physicians' estimates were better (i.e., expertise works) but that increased exposure to a disease leads to an upward bias in estimated mortality (i.e., increased familiarity with a subject can bias one's judgment.) In the context of securities analysis, this suggests that longer term experience analyzing a particular firm may not lead to better accuracy. Altering the cliché, it may be that familiarity breeds bias.

Nass (1994) also provides troubling results, finding that administrators in large organizations whose jobs require them to process information primarily learn knowledge (stored information, common to all) from job experience, rather than skills (process and procedures, possibly unique to the individual.) In the context of securities analysis, much effort is taken to ensure that access to knowledge is uniform across market participants (e.g., public availability of SEC filings, regulation FD, etc.) Thus, Nass' work suggests that there is less value to be gained from analyst experience, if that experience leads only to an increase in knowledge and not skills.

On the other hand, in the context of audit judgments, Abdolmohammadi and Wright (1987) find that experience increases performance for unstructured (complex, possibly unique) and, to a lesser extent, semistructured tasks, but not for structured (simple) tasks. This bodes well for the value of experience with respect to earnings forecast accuracy, as such analysis represents a complex, unstructured task. Similarly, in the context of mutual fund management, Golec (1996) finds that, "the most significant [and positive] predictor of performance is the length of time a manager has managed his or her fund (tenure)" (abstract.) In the context of hedge fund management, Maxam, et al (2006) see mixed results when studying the effect of experience, measured in this case as prior work experience, on fund performance.

Most closely related to this study, there are a number of papers that examine the relationship between experience and performance specifically in the context of the accuracy of analyst forecasts of future firm earnings. Mikhail et al (1997) studied a limited set of analysts - those who had provided at least 32 quarters (eight years) of earnings estimates for a particular firm - using forecasts of quarterly income from the Zacks Investment Research database for 1980-1995. They find that forecast accuracy grows as an analyst's experience in forecasting earnings for that firm increases and, also, that market participants appear to place more value on the forecasts of more experienced analysts. They interpret their results as evidence of the "learning by doing" (human capital development) hypothesis.

Clement (1999) finds that forecast accuracy is positively associated with analyst experience. Forecast accuracy is shown to be related to both general experience (the number of quarters the analyst has provided earnings estimates for any firm) and specific experience (the number of quarters the analyst has provided earnings estimates for the firm in question.) In contrast with Mikhail et al (1997), Clement interprets greater experience as a proxy for greater inherent ability and skill rather than human capital development. Clement's study examines forecasts of quarterly earnings from the Thomson Financial I/B/E/S database for 1983-1994.

Jacob et al (1999) try to discern between analyst aptitude (native ability) and experience (learning-by-doing or human capital development) in an examination of earnings forecasts from the Zacks database for 1981-1992. They find, as have others, that specific analyst experience (the number of quarters for which the analyst has provided earnings forecasts for the firm) is positively related to forecast accuracy. However, when they control for specific analyst/firm effects in the regression equations, specific analyst experience is no longer significantly related to forecast accuracy. They interpret this as evidence that analyst experience as commonly measured is a proxy for survivorship bias and thus reflects underlying ability, rather than human capital (skill) development.

\section{DATA AND METHODS}

The analysts' estimates of per share annual firm operating earnings that we examine in this study come from the Thomson Financial First Call I/B/E/S (Institutional Brokers Estimates System) U.S. Detail History 
database. The full file contains slightly more than seven million dated estimates made by 15,595 analysts regarding 14,999 firms for fiscal years ending in 1983 through early 2003. This includes many duplicate (consecutive) estimates by the same analyst for each firm/year pair; we look only at the last estimate made by a given analyst for a given firm for a given year. The database also provides actual per share operating earnings for each year.

In contrast to most of the extant literature, we examine forecasts of annual earnings, rather than quarterly earnings. We believe that annual earnings and estimates of them are more closely followed by market participants. This suggests to us that analysts will place more effort or emphasis on these forecasts.

The proper measure of earnings forecast accuracy is open to debate. Because estimated earnings and actual earnings can be negative or positive or a mixture of both, we measure the absolute value of the difference between actual earnings and the last estimate of those earnings that was provided by the analyst. This means that we are measuring absolute forecast error (AFE) not forecast accuracy. We must keep this in mind when interpreting the signs of regression coefficients.

The scale of this difference will mean different things for different firms. A $\$ 0.10$ AFE means more if a firm's share price is $\$ 10.00$ than if it is $\$ 100.00$; therefore, as our first measure of forecast accuracy (error) we divide the AFE by end of period share price $(A F E / P)$ to create a relative measure of forecast accuracy. This measure was employed by Mikhail et al (1997). Jacob et al (1999) show that AFE/P can be decomposed into AFE/E $\times$ E/P, where $\mathrm{E}$ is actual earnings. They show that the average AFE/P across analysts varies widely over time, but that this variation comes from variation in $\mathrm{E} / \mathrm{P}$ (the inverse of the $\mathrm{P} / \mathrm{E}$ ratio), which is a market pricing factor that is independent of earnings forecasts. They show that the average of AFE/E across analysts, in contrast, is relatively stable from year to year. Therefore, as a second measure of relative forecast accuracy, we divide the absolute forecast error by the absolute value of actual earnings $(A F E / E)$.

In addition, some investors will be more directly concerned about the relative performance between analysts for a particular firm than the average performance relative to earnings or share price, therefore we construct a third measure of forecast accuracy equal to the absolute forecast error less the mean of the absolute forecast error of all analysts following the firm for that fiscal year divided by that mean ((AFE-avg)/avg). Similar measures of relative performance have been employed by numerous researchers (e.g., Brown and Mohd (2003), Clement (1999), Jacob et al (1999), and others.)

We estimate otherwise identical cross-sectional regressions using the three measures of forecast accuracy discussed above. Our tests are conducted initially over the full, 20-year sample period (1983-2002). In addition, we divide the sample into four 5-year subperiods (1998-2002, 1993-1997, 1988-1992, and 1983-1987) and repeat our tests for each subperiod.

We are particularly interested in whether measures of analyst experience maintain a significant (and, we assume, positive) relationship with forecast accuracy over independent sample periods. We measure analyst experience in two ways. We measure general experience as the number of years during the sample period beyond the current year in which the analyst produced an earnings forecast for any firm. For the full sample, general experience can take any discrete value between 0 and 19. For each of the subperiods, it can take any discrete value between 0 and 4 . In addition, we measure specific experience as the number of years during the sample period beyond the current year in which the analyst produced an earnings estimate for the specific firm in question.

Our tests consist of cross-sectional regressions of forecast accuracy on general and specific analyst experience. For the full sample period and each subperiod we include only one observation for each analyst/firm pair, using the last earnings forecast provided by the analyst for that firm during the last year of the sample period. For example, for the latest subperiod (1998-2002), we measure AFE as absolute value of the actual 2002 operating earnings per share less the last forecast of that year's earnings provided by the analyst. The analyst's general experience and specific experience are measured over the 1998-2001 period. The accuracy of analyst's forecasts of 1998, 1999, 2000, and 2001 earnings (if available) are not considered. 
In related tests for the four subperiods and the full sample period, we examine the relationship between the likelihood of producing a conservative estimate (an earnings forecast that is less than the actual earnings) and analyst experience. We use logistic regressions for the four subperiods and the full sample period with a dummy dependent variable equal to one if the earnings forecast is less than actual earnings for the period, and zero otherwise.

In our tests, in addition to these two measures of analyst experience, we employ five control variables. The first is the number of firms for which the analyst provided an earnings forecast during the final year. The second is the number of analysts who provided an earnings forecast for the firm for the final year. The third is a dummy variable equal to one if actual earnings exceeded the analyst's forecast (i.e., if the analyst's estimate was conservative) and zero otherwise; we call this low estimate. (Note: this is the dependent variable in the logistic regressions.) The fourth is a dummy variable called positive earnings which is equal to one if actual earnings were positive and zero otherwise. The fifth is a measure of the relative untimeliness or staleness (age) of the analyst's estimate, measured as the number of days between the date of the analyst's forecast and the date that the year being forecast ended, less the average of this number for all analysts following the firm in this year.

Summary statistics for the three forecast variables, the two experience variables, and the five controls are provided in Table 1. Panel (a) provides information for the full sample period, while panels (b) through (e) provide the same statistics for each of the four subperiods, from most recent to most distant. Panels (a) and (b) differ only in the measures of analyst experience. This means that tests of the full sample period (1983-2002) and the latest 5-year subperiod (1998-2002) consider the same analyst/firm forecast accuracy and the same values of the control variables, differing only in the value of the experience variables.

There is significant variation in all three forecast error variables. For example, in 2002, the average absolute forecast error was approximately 9 percent of the firm's stock price, but the standard deviation of the errors was 190 percent of stock price. For the full 20 -year sample period, analysts have, on average, provided earnings forecasts for approximately 6 years. On average, analysts have provided earnings forecasts for the firm in question for only 2 years, so the average difference between specific and general experience is about 4 years. On average, in 2002, each analyst provided earnings forecasts for $181 / 2$ firms and each firm was followed by slightly more than 17 analysts. 53 percent of forecasts were conservative (less than actual earnings) and 77 percent of actual earnings were positive.

\section{RESULTS}

The results of our tests on forecast accuracy are provided in Table 2. The second column of each panel provides results for the full sample period. The third through sixth columns provide results for the four subperiods from the most recent (1998-2002) to the most distant (1983-1987).

Panel (a) provides regression coefficient estimates and their p-values when forecast error is measured as absolute forecast error divided by share price. Overall, these results suggest that Jacob et al's (1999) critique of this measure of forecast error has merit. The explanatory power of each regression is very low; less than one percent. Analyst experience appears to have no relationship to forecast error, except for the negative relationship for general experience in the 1983-1987 and 1988-1992 subperiods. In those two periods, more experienced analysts were significantly more accurate in their forecasts.

Of the control variables, neither the number of firms the analyst follows during the period nor the timeliness of the forecast are significantly related to forecast error. The dummy measuring a low or conservative forecast (one that is below actual earnings) is significant for two of the four subperiods, but its sign differs across the two. A conservative estimate is associated with larger forecast errors in the 1983-1987 subperiod and with smaller forecast errors in the 1993-1997 subperiod. Only the number of analysts following the firm and the dummy indicating positive earnings are consistently (and negatively) related to forecast error, meaning a positive relationship with forecast accuracy. That is, when more analysts follow a firm, estimates are likely to be more accurate and it appears that estimates for firms that have positive earnings are generally more accurate. 
Panel (b) provides regression coefficient estimates and their p-values when forecast error is measured as absolute forecast error divided by the absolute value of actual operating earnings for the year. The explanatory power of these regressions is better than for the AFE/P measure of forecast error, but is still less than five percent for all subperiods.

Of particular interest for this study, general experience is negatively associated with forecast error (positively associated with forecast accuracy) for only one of the four subperiods and not for the full sample period. There is stronger evidence that specific experience leads to greater forecast accuracy, with a statistically significant negative relationship between specific experience and forecast error for two of the four subperiods and for the full sample period.

For the AFE/E measure of forecast error, all control variables are significant for the full sample period and have their expected signs - negative for number of analysts, low estimate and positive earnings and positive for number of firms and untimeliness. All of these variables are significant and have the same signs in each of the four subperiods with two exceptions. The number of firms followed by the analyst is positively associated with forecast error in the 1988-1992 and 1998-2002 subperiods. In addition, the number of analysts following the firm is significant in all four subperiods, but in the earliest (1983-1987), it has a positive sign.

Panel (c) provides regression coefficient estimates and their p-values when forecast error is measured relative to the errors of other analysts (as the absolute forecast error minus the mean of the AFE of all analysts following the firm for that fiscal period ending date divided by the mean of the AFE of all analysts following the firm for that fiscal period ending date.) The explanatory power of this specification is fairly high at about 33 percent for the full sample period down to a low of more than 12 percent for the 1988-1992 subperiod.

For this measure of forecast error, the significance of the control variables is very different than for AFE/E. Neither the number of analysts following the firm nor the dummy indicating positive earnings is significant over the full period or in any subperiod. In contrast, the number of firms followed by the analyst and the untimeliness of the analyst's estimate are both positively related to forecast error (negatively related to forecast accuracy.) This means that analysts who follow fewer firms and analysts who release forecasts closer to the end of the period produce more accurate estimates. The low (conservative) estimate dummy variable is also significant for the full sample period and three of the four subperiods (except the first, 1983-1997). Its positive coefficient value suggests that analysts who are conservative (forecast < actual) produce less accurate forecasts relative to other analysts. This is opposite the results in panel (b) when forecast error is measured as AFE/E and not relative to the performance of other analysts for the same firm's earnings.

For the (AFE - avg)/avg measure of forecast error, general experience has a significant and negative association with forecast error (i.e., more experienced analysts are more accurate) for three of the four subperiods (1983-1987 excepted), but it is not significant for the full sample period (when general experience can range from 019.) Further, specific experience is negatively associated with forecast error in only two subperiods (1988-1992 and 1993-1997) and not across the full sample period.

The results for our additional tests on forecast conservativeness (the likelihood of forecast earnings to be less than actual earnings) are provided in Table 3. As shown, there is consistent evidence across the subperiods (and the full sample period) that analysts' estimates are less likely to be conservative when actual earnings are positive and more likely to be conservative when the estimate is made further from the end of the period being forecast.

\section{CONCLUSIONS}

In this study, we add to two bodies of research; a more general one that examines connections between past experience and task performance and a more specific one that examines the connections between the many characteristics of financial market professionals (including their prior work experience) and the quality of their work. In particular, we examine the link between the job experience of securities analysts and the accuracy of the 
earnings forecasts that they produce. We employ a much longer sample period than prior studies (20 years, from 1983 through 2002) and compare results across four non-overlapping subperiods.

We examine three measures of forecast accuracy that have been employed in earlier research. We find evidence that the criticism made of one of these measures (absolute forecast error divided by share price) by Jacob et al (1999) has merit. We also examine the joint impact of two measures of experience, general and specific. We find evidence that experience leads to better job performance (better forecast accuracy), but this result varies and is not uniform across the distinct time periods that we study, nor is it uniform across different measures of forecast accuracy. The relationship is strongest for our second two measures of forecast accuracy (AFE/E and (AFEavg)/avg).

We also look at factors impacting the conservativeness of an analyst's estimate (the likelihood that the earnings estimate will be less than actual earnings.) General and specific analyst experience show an inconsistent relationship with conservativeness. There is consistent evidence that analysts' estimates are less likely to be conservative when actual earnings are positive and more likely to be conservative when the estimate is made further from the end of the period being forecast.

\section{ACKNOWLEDGEMENT}

The authors gratefully acknowledge the contribution of Thomson Financial for providing earnings per share forecast data, available through the Institutional Brokers Estimate System (I/B/E/S). This data has been provided as part of a broad academic program to encourage earnings expectations research.

\section{AUTHOR INFORMATION}

Rich Fortin is a professor of finance at New Mexico State University in Las Cruces, NM. rfortin@nmsu.edu.

James Gilkeson, CFA is an associate professor of finance at the University of Central Florida in Orlando, FL. jim.gilkeson@bus.ucf.edu.

Stuart Michelson is the Roland \& Sarah George professor of finance at Stetson University in DeLand, FL. michels@stetson.edu .

\section{REFERENCES}

1. Abdolmohammadi, Mohammad and Arnold Wright, An Examination of the Effects of Experience and Task Complexity on Audit Judgments, The Accounting Review 62(1), January 1987, 1-13.

2. Brown, Lawrence D., How Important is Past Analyst Forecast Accuracy? Financial Analysts Journal 57(6), November/December 2001, 44-49.

3. Brown, Lawrence D. and Emad Mohd, The Predictive Value of Analyst Characteristics, Journal of Accounting, Auditing \& Finance 18(4), Fall 2003, 625-647.

4. Christensen-Szalanski, Jay J. J., Don E. Beck, Carlyn M. Christensen-Szalanski, and Thomas D. Koepsell, Effects of Expertise and Experience on Risk Judgments, Journal of Applied Psychology 68(2), 1983, 278284.

5. Chopra, Vijay Kumar, Why so much error in analysts' earnings forecasts? Financial Analysts Journal 54(6), November/December 1998, 35-42.

6. Clement, Michael B., Analyst Forecast Accuracy: Do Ability, Resources, and Portfolio Complexity Matter? Journal of Accounting and Economics 27(3), June 1999, 285-303.

7. Cooper, Rick, Theodore Day, and Craig Lewis, Follow the leader: A study of individual analysts' earnings forecasts, Journal of Financial Economics 61(3), September 2001, 383-416.

8. Fortin, Rich, and Stuart Michelson, The Earnings Forecast Accuracy of Financial Analysts Who are CFA Charterholders, Journal of Investing 15(3), Fall 2006, 19-24. 
9. Golec, Joseph H., The Effects of Mutual Fund Managers' Characteristics on Their Portfolio Performance, Risk and Fees, Financial Services Review 5(2), 1996, 133-148.

10. Harris, Richard D. F., The Accuracy, Bias and Efficiency of Analyst' Long Run Earnings Growth Forecasts, Journal of Business, Finance, and Accounting 26(5\&6), June/July 1999, 725-755.

11. Jacob, John, Thomas Z. Lys, and Margaret A. Neale, Expertise in Forecasting Performance of Security Analysts, Journal of Accounting and Economics 28(1), November 1999, 51-82.

12. Maxam, Clark L, Ehsan Nikbakht, Milena Petrova and Andrew C. Spieler, Manager Characteristics and Hedge Fund Performance, Journal of Applied Finance 16(2), Fall 2006, 57-70.

13. Mikhail, Michael B, Beverly R. Walther, and Richard H. Willis, Do Security Analysts Improve Their Performance with Experience, Journal of Accounting Research 35(supplement), 1997, 131-157.

14. Nass, Clifford, Knowledge or Skills: Which Do Administrators Learn from Experience? Organization Science 5(1), February 1994, 38-50.

15. Sinha, Preveen, Lawrence D. Brown, and Somnath Das, A Re-Examination of Financial Analyts' Differential Earnings Forecast Accuracy, Contemporary Accounting Research 14(1), 1-42.

16. Sougiannis, Theodore, and Takashi Yackura, The Accuracy and Bias of Equity Values Inferred from Analysts’ Earnings Forecasts, Journal of Accounting, Auditing and Finance 16(4), Fall 2001, 331-362.

17. Stickel, Scott E., Reputation and Performance Among Security Analysts, The Journal of Finance 47(5), December 1992, 1811-1836.

Table 1: Summary Statistics

Panel (a): full sample (1983-2002)

\begin{tabular}{|c|c|c|c|c|}
\hline variable & mean & $\begin{array}{l}\text { standard } \\
\text { deviation }\end{array}$ & minimum & maximum \\
\hline $\mathrm{AFE} / \mathrm{P}$ & $\overline{0.0898}$ & 1.9090 & 0.0 & 230.0 \\
\hline AFE/E & 0.3187 & 1.6044 & 0.0 & 101.0 \\
\hline (AFE-avg)/avg & 0.0000 & 1.0711 & -1.0 & 20.7 \\
\hline general experience & 5.9455 & 5.5601 & 0.0 & 19.0 \\
\hline specific experience & 2.0552 & 2.9207 & 0.0 & 19.0 \\
\hline number of firms & 18.5957 & 72.5353 & 1.0 & 577.0 \\
\hline number of analysts & 17.1621 & 11.3680 & 1.0 & 61.0 \\
\hline low estimate & 0.5271 & 0.4993 & 0.0 & 1.0 \\
\hline positive earnings & 0.7698 & 0.4210 & 0.0 & 1.0 \\
\hline untimeliness & -0.0007 & 81.7219 & -216.2 & 287.2 \\
\hline
\end{tabular}

Panel (b): 1998-2002

\begin{tabular}{|c|c|c|c|c|}
\hline variable & mean & $\begin{array}{l}\text { standard } \\
\text { deviation }\end{array}$ & $\underline{\text { minimum }}$ & $\underline{\text { maximum }}$ \\
\hline $\mathrm{AFE} / \mathrm{P}$ & 0.0898 & 1.9090 & 0.0 & 230.0 \\
\hline $\mathrm{AFE} / \mathrm{E}$ & 0.3187 & 1.6044 & 0.0 & 101.0 \\
\hline (AFE-avg)/avg & 0.0000 & 1.0711 & -1.0 & 20.7 \\
\hline general experience & 2.8034 & 1.4902 & 0.0 & 4.0 \\
\hline specific experience & 1.4143 & 1.4463 & 0.0 & 4.0 \\
\hline number of firms & 18.5957 & 72.5353 & 1.0 & 577.0 \\
\hline number of analysts & 17.1621 & 11.3680 & 1.0 & 61.0 \\
\hline low estimate & 0.5271 & 0.4993 & 0.0 & 1.0 \\
\hline positive earnings & 0.7698 & 0.4210 & 0.0 & 1.0 \\
\hline untimeliness & -0.0007 & 81.7219 & -216.2 & 287.2 \\
\hline
\end{tabular}


Panel (c): 1993-1997

\begin{tabular}{|lcccc|}
\hline variable & $\underline{\text { mean }}$ & $\begin{array}{c}\text { standard } \\
\text { deviation }\end{array}$ & $\underline{\text { minimum }}$ & $\underline{\text { maximum }}$ \\
AFE/P & 0.0302 & 0.6575 & 0.0 & 83.4 \\
AFE/E & 0.3512 & 2.8557 & 0.0 & 309.3 \\
(AFE-avg)/avg & 0.0000 & 0.9200 & -1.0 & 17.6 \\
general experience & 2.8913 & 1.4302 & 0.0 & 4.0 \\
specific experience & 1.5160 & 1.4953 & 0.0 & 3.0 \\
number of firms & 15.6392 & 40.4869 & 1.0 & 57.0 \\
number of analysts & 14.3847 & 10.6043 & 1.0 & 1.0 \\
low estimate & 0.5228 & 0.4995 & 0.0 & 1.0 \\
positive earnings & 0.8794 & 0.3257 & 0.0 & 288.2 \\
untimeliness & -0.0040 & 75.6596 & -201.6 & \\
\hline
\end{tabular}

Panel (d): 1988-1992

\begin{tabular}{|lcccc|}
\hline variable & $\underline{\text { mean }}$ & $\begin{array}{c}\text { standard } \\
\text { deviation }\end{array}$ & $\underline{\text { minimum }}$ & $\frac{\text { maximum }}{289.7}$ \\
AFE/P & 0.0417 & 1.8464 & 0.0 & 109.5 \\
AFE/E & 0.4352 & 2.4262 & 0.0 & 13.7 \\
(AFE-avg)/avg & 0.0000 & 0.8524 & -1.0 & 4.0 \\
general experience & 3.1637 & 1.0942 & 0.0 & 4.0 \\
specific experience & 1.8875 & 1.4095 & 0.0 & 345.0 \\
number of firms & 19.3363 & 41.7375 & 1.0 & 48.0 \\
number of analysts & 16.1826 & 10.6748 & 1.0 & 1.0 \\
low estimate & 0.4380 & 0.4962 & 0.0 & 1.0 \\
positive earnings & 0.8894 & 0.3137 & 0.0 & 278.4 \\
untimeliness & -0.0012 & 71.9249 & -195.6 & \\
\hline
\end{tabular}

Panel (e): 1983-1987

\begin{tabular}{|c|c|c|c|c|}
\hline variable & mean & $\begin{array}{l}\text { standard } \\
\text { deviation }\end{array}$ & minimum & maximum \\
\hline$\overline{\mathrm{AFE} / \mathrm{P}}$ & 0.3891 & 26.8936 & 0.0 & 2666.0 \\
\hline $\mathrm{AFE} / \mathrm{E}$ & 1.3797 & 13.4955 & 0.0 & 574.0 \\
\hline (AFE-avg)/avg & 0.0000 & 0.8730 & -1.0 & 20.5 \\
\hline general experience & 2.4681 & 1.5167 & 0.0 & 4.0 \\
\hline specific experience & 1.3449 & 1.4376 & 0.0 & 4.0 \\
\hline number of firms & 22.4082 & 63.0453 & 1.0 & 491.0 \\
\hline number of analysts & 20.6855 & 13.1686 & 1.0 & 54.0 \\
\hline low estimate & 0.4000 & 0.4899 & 0.0 & 1.0 \\
\hline positive earnings & 0.8725 & 0.3335 & 0.0 & 1.0 \\
\hline untimeliness & 0.0014 & 88.1412 & -209.0 & 278.8 \\
\hline
\end{tabular}

Three measures of earnings forecast accuracy are employed, all based on absolute forecast error (AFE), which is equal to the absolute value of the difference between actual operating earnings for the year (last year of the sample period) and the last forecast of those earnings provided by the analyst. AFE/P is AFE divided by end of period share price. AFE/E is AFE divided by the absolute value of actual operating earnings per share. (AFE-avg)/avg is AFE less the average AFE for other analysts providing a forecast of the firm's earnings for the year divided by that average. General experience is the number of years during the sample period prior to the current year in which this analyst provided a forecast of any firm's earnings. Specific experience is the number of years during the sample period prior to the current year in which this analyst provided a forecast of this firm's earnings. Number of firms is the number of firms for which the analyst provides an earnings forecast during the current year. Number of analysts is the number of analysts who provide an earnings forecast for this firm in the current year. Low estimate is a dummy variable equal to 1 if the earnings forecast is less than the actual earnings (a measure of conservativeness) and 0 otherwise. Positive earnings is a dummy variable equal to 1 if actual earnings are positive and 0 otherwise. Untimeliness is equal to the number of days between the end of the year for which earnings are being forecast and the date the forecast is made less the average of this measure for all analysts providing an earnings forecast for this firm and year. 
Table 2: Cross-sectional Regression of Forecast Accuracy on Analyst Experience

(a) AFE/P (absolute forecast error / share price)

\begin{tabular}{|c|c|c|c|c|c|}
\hline \multirow{3}{*}{ general experience } & $1983-2002$ & $1998-2002$ & 1993-1997 & $1988-1992$ & $1983-1987$ \\
\hline & -0.0002 & 0.0109 & 0.0001 & -0.0373 & -0.2604 \\
\hline & 0.13 & 0.19 & 0.96 & 0.00 & 0.05 \\
\hline \multirow{2}{*}{ specific experience } & 0.0008 & -0.0040 & 0.0001 & 0.0068 & 0.1420 \\
\hline & 0.85 & 0.64 & 0.97 & 0.48 & 0.31 \\
\hline \multirow[t]{2}{*}{ number of firms } & -0.0001 & -0.0001 & 0.0001 & 0.0001 & -0.0003 \\
\hline & 0.50 & 0.33 & 0.15 & 0.69 & 0.92 \\
\hline \multirow[t]{2}{*}{ number of analysts } & -0.0050 & -0.0049 & -0.0014 & -0.0032 & -0.0347 \\
\hline & 0.00 & 0.00 & 0.00 & 0.00 & 0.00 \\
\hline \multirow[t]{2}{*}{ low estimate } & -0.0115 & -0.0115 & -0.0207 & 0.0196 & 0.6367 \\
\hline & 0.58 & 0.58 & 0.00 & 0.40 & 0.05 \\
\hline \multirow[t]{2}{*}{ positive earnings } & -0.3037 & -0.3036 & -0.15477 & -0.2998 & -0.57611 \\
\hline & 0.00 & 0.00 & 0.00 & 0.00 & 0.23 \\
\hline \multirow[t]{2}{*}{ untimeliness } & 0.0002 & 0.0002 & 0.0001 & 0.0001 & 0.0004 \\
\hline & 0.13 & 0.16 & 0.19 & 0.44 & 0.84 \\
\hline number of observations & 35,151 & 35,151 & 37,855 & 26,578 & 29,608 \\
\hline adjusted r-square & $0.55 \%$ & $0.55 \%$ & $0.74 \%$ & $0.32 \%$ & $0.03 \%$ \\
\hline
\end{tabular}

(b) AFE/E (absolute forecast error / absolute value of actual earnings)

\begin{tabular}{|c|c|c|c|c|c|}
\hline \multirow{3}{*}{ general experience } & $1983-2002$ & 1998-2002 & 1993-1997 & 1988-1992 & 1983-1987 \\
\hline & -0.0031 & -0.0080 & -0.0475 & -0.0133 & -0.0099 \\
\hline & 0.11 & 0.25 & 0.00 & 0.39 & 0.88 \\
\hline \multirow{2}{*}{ specific experience } & -0.0086 & -0.0039 & -0.0251 & 0.0087 & -0.1232 \\
\hline & 0.01 & 0.58 & 0.04 & 0.49 & 0.08 \\
\hline \multirow[t]{2}{*}{ number of firms } & 0.0004 & 0.0005 & 0.0005 & 0.0014 & 0.0010 \\
\hline & 0.00 & 0.00 & 0.16 & 0.00 & 0.43 \\
\hline \multirow[t]{2}{*}{ number of analysts } & -0.0022 & -0.0023 & -0.0033 & -0.0073 & 0.0713 \\
\hline & 0.00 & 0.00 & 0.02 & 0.00 & 0.00 \\
\hline \multirow{2}{*}{ low estimate } & -0.2230 & -0.2228 & -0.2068 & -0.2513 & -1.3478 \\
\hline & 0.00 & 0.00 & 0.00 & 0.00 & 0.00 \\
\hline \multirow[t]{2}{*}{ positive earnings } & -0.4994 & -0.5004 & -1.0876 & -1.3493 & -1.0023 \\
\hline & 0.00 & 0.00 & 0.00 & 0.00 & 0.00 \\
\hline \multirow[t]{2}{*}{ untimeliness } & 0.0023 & 0.0024 & 0.0018 & 0.0018 & 0.0066 \\
\hline & 0.00 & 0.00 & 0.00 & 0.00 & 0.00 \\
\hline number of observations & 35,187 & 35,187 & 37,870 & 26,591 & 29,624 \\
\hline adjusted r-square & $4.10 \%$ & $4.10 \%$ & $2.14 \%$ & $4.08 \%$ & $0.95 \%$ \\
\hline
\end{tabular}




\begin{tabular}{|c|c|c|c|c|c|}
\hline 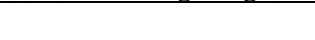 & $\underline{1983-2002}$ & $1998-2002$ & 1993-1997 & 1988-1992 & 1983-1987 \\
\hline \multirow{2}{*}{ general experience } & -0.0005 & -0.0073 & -0.0068 & -0.0124 & 0.0092 \\
\hline & 0.63 & 0.04 & 0.07 & 0.02 & 0.02 \\
\hline \multirow[t]{2}{*}{ specific experience } & -0.0002 & 0.0010 & -0.0127 & -0.0112 & -0.0067 \\
\hline & 0.94 & 0.80 & 0.00 & 0.01 & 0.11 \\
\hline \multirow[t]{2}{*}{ number of firms } & 0.0005 & 0.0005 & 0.0005 & 0.0007 & 0.0003 \\
\hline & 0.00 & 0.00 & 0.00 & 0.00 & 0.00 \\
\hline \multirow[t]{2}{*}{ number of analysts } & 0.0000 & 0.0000 & 0.0006 & 0.0005 & 0.0001 \\
\hline & 0.93 & 0.95 & 0.16 & 0.29 & 0.72 \\
\hline \multirow[t]{2}{*}{ low estimate } & 0.1018 & 0.1018 & 0.0776 & 0.0755 & 0.0033 \\
\hline & 0.00 & 0.00 & 0.00 & 0.00 & 0.74 \\
\hline \multirow[t]{2}{*}{ positive earnings } & -0.0144 & -0.0144 & -0.0180 & -0.0204 & -0.0020 \\
\hline & 0.20 & 0.20 & 0.19 & 0.20 & 0.89 \\
\hline \multirow[t]{2}{*}{ untimeliness } & 0.0075 & 0.0075 & 0.0046 & 0.0041 & 0.0036 \\
\hline & 0.00 & 0.00 & 0.00 & 0.00 & 0.00 \\
\hline number of observations & 35,187 & 35,187 & 37,870 & 26,591 & 29,624 \\
\hline adjusted r-square & $32.71 \%$ & $32.71 \%$ & $14.31 \%$ & $12.37 \%$ & $12.96 \%$ \\
\hline
\end{tabular}

P-values of coefficients appear below the estimate. Coefficients that are significantly different from zero with 90 percent or greater confidence are in bold font. Dependent variable in panel (a) is absolute forecast error (AFE) divided by end of period share price. Dependent variable in panel (b) is AFE divided by the absolute value of actual operating earnings per share. Dependent variable in panel (c) is AFE less the average AFE for other analysts providing a forecast of the firm's earnings for the year divided by that average. Independent variables are identical across the panels: general experience is the number of years during the sample period prior to the current year in which this analyst provided a forecast of any firm's earnings; specific experience is the number of years during the sample period prior to the current year in which this analyst provided a forecast of this firm's earnings; number of firms is the number of firms for which the analyst provides an earnings forecast during the current year; number of analysts is the number of analysts who provide an earnings forecast for this firm in the current year; low estimate is a dummy variable equal to 1 if the earnings forecast is less than the actual earnings (a measure of conservativeness) and 0 otherwise; positive earnings is a dummy variable equal to 1 if actual earnings are positive and 0 otherwise; and untimeliness is equal to the number of days between the end of the year for which earnings are being forecast and the date the forecast is made less the average of this measure for all analysts providing an earnings forecast for this firm and year 
Table 3: Logistic Regressions of Forecast Conservatism on Analyst Experience

\begin{tabular}{|c|c|c|c|c|c|}
\hline & $1983-2002$ & $1998-2002$ & 1993-1997 & $1988-1992$ & $1983-1987$ \\
\hline \multirow{2}{*}{ general experience } & 0.0033 & 0.0003 & -0.0133 & -0.0319 & -0.0003 \\
\hline & 0.19 & 0.97 & 0.13 & 0.02 & 0.98 \\
\hline \multirow[t]{2}{*}{ specific experience } & 0.0058 & 0.0021 & 0.0258 & 0.0345 & -0.0275 \\
\hline & 0.19 & 0.82 & 0.00 & 0.00 & 0.01 \\
\hline \multirow[t]{2}{*}{ number of firms } & -0.0001 & 0.0000 & 0.0004 & -0.0007 & 0.0004 \\
\hline & 0.58 & 0.98 & 0.15 & 0.02 & 0.07 \\
\hline \multirow[t]{2}{*}{ number of analysts } & -0.0029 & -0.0028 & 0.0070 & 0.0045 & 0.0006 \\
\hline & 0.00 & 0.00 & 0.00 & 0.00 & 0.56 \\
\hline \multirow[t]{2}{*}{ positive earnings } & -0.5299 & -0.5244 & -1.1157 & -0.9763 & -1.8351 \\
\hline & 0.00 & 0.00 & 0.00 & 0.00 & 0.00 \\
\hline \multirow[t]{2}{*}{ untimeliness } & 0.0022 & 0.0022 & 0.0015 & 0.0020 & 0.0004 \\
\hline & 0.00 & 0.00 & 0.00 & 0.00 & 0.01 \\
\hline number of observations & 35,187 & 35,187 & 37,870 & 26,591 & 29,624 \\
\hline percent concordant & $56.8 \%$ & $56.7 \%$ & $57.5 \%$ & $57.0 \%$ & $57.0 \%$ \\
\hline
\end{tabular}

P-values of coefficients appear below the estimate. Coefficients that are significantly different from zero with 90 percent or greater confidence are in bold font. Dependent variable is a dummy $=1$ if the forecast of earnings is less than the actual earnings and zero otherwise. Independent variables: general experience is the number of years during the sample period prior to the current year in which this analyst provided a forecast of any firm's earnings; specific experience is the number of years during the sample period prior to the current year in which this analyst provided a forecast of this firm's earnings; number of firms is the number of firms for which the analyst provides an earnings forecast during the current year; number of analysts is the number of analysts who provide an earnings forecast for this firm in the current year; low estimate is a dummy variable equal to 1 if the earnings forecast is less than the actual earnings (a measure of conservativeness) and 0 otherwise; positive earnings is a dummy variable equal to 1 if actual earnings are positive and 0 otherwise; and untimeliness is equal to the number of days between the end of the year for which earnings are being forecast and the date the forecast is made less the average of this measure for all analysts providing an earnings forecast for this firm and year

\section{NOTES}

